University of New Mexico

UNM Digital Repository

Mathematics and Statistics Faculty and Staff

Publications

Academic Department Resources

2019

How to Celebrate 24 New Year's Eves in a Single Year!

Florentin Smarandache

Follow this and additional works at: https://digitalrepository.unm.edu/math_fsp

Part of the Astrophysics and Astronomy Commons, Geophysics and Seismology Commons, Mathematics Commons, and the Other Earth Sciences Commons 
OCTOGON MATHEMATICAL MAGAZINE

Vol. 27, No.1, April 2019, pp 419-423

Print: ISSN 1222-5657, Online: ISSN 2248-1893

http://www.uni-miskolc.hu/ matsefi/Octogon/

\title{
How to Celebrate 24 New Year's Eves in a Single Year!
}

\author{
Florentin Smarandache \\ University of New Mexico \\ Mathematics Department \\ 705 Gurley Ave., Gallup, NM 87301, USA
}

\section{Introduction.}

New Year's Eve 2018 reaches me on Jeju Island, South Korea, in the East China Sea. While I had spent New Year's Eve 2017 in Galapagos Islands, in the Pacific.

We can celebrate 24 New Year's Eves in a single year, moving to the West - for example in an orbital spacecraft - (in the reverse sense of Earth's rotation around its axis) at a faster angular speed than Earth's rotation, jumping from one time-zone to another, and starting from the International Date Line.

$\{$ In this paper we are referring to the solar day, hence to the angular speed of Earth's rotation on its axis with respect to the Sun. \}

But a person being on the Geographical (Terrestrial) North Pole or on the Geographical (Terrestrial) South Pole celebrates the New Year Ever for 24 hours continuously!!

\section{Astronomical Data.}

The solar day (time that our planet rotates around its axis, considering the Sun as referential system) is 24 hours, but the sidereal day (time that our planet rotates around its axis, but considering the fixed stars as referential system) is 23 hours, 56 minutes, and 4.09 seconds $[1,2]$.

The rotation from West to East is counter-clockwise, as seen from the North Pole Star (Polaris). 
The Earth's rotation duration had and will still be changing over astronomical time (in the last period it was decelerating - making the day to increase from 21 to 24 hours), due to the Moon's gravitational field interacting with the Earth's gravitational field.

Similarly, the Earth's rotation axis changes with respect to the planet's crust [polar motion], as well as with respect to the fixed stars [procession and nutation].

Therefore, we may compute two angular velocities:

a) With respect to the Sun - as referential system (i.e. when a day $=24$ hours $=86,400$ seconds), the angular velocity of Earth's rotation on its axis, is: $2 \pi$ radians $/ 86,400$ seconds $\simeq 7.272 \times 10^{-5} \mathrm{rad} / \mathrm{s}$.

b) And with respect to the fixed stars - as referential system (i.e. when a day $=23$ hours, 56 minutes, and 4.09 seconds $=86,164.09$ seconds), the angular velocity of Earth's rotation on its axis, is:

$2 \pi$ radians/86,164.09 seconds $\simeq 7.292 \times 10^{-5} \mathrm{rad} / \mathrm{s}$.

While the angular velocities (with respect to the Sun, or with respect to the fixed stars) are the same for all points on the Earth, the linear movement of a point on the equatorial nearly circular orbit $\{1,669.8 \mathrm{~km} / \mathrm{h}$ (with respect to the Sun), or $1,674.4 \mathrm{~km} / \mathrm{h}$ (with respect to the fixed stars) $\}$ is bigger in comparison to the linear movement of a point on a different latitude.

\section{International Date Line.}

The International Date Line starts from the North Pole, passing through the Arctic Ocean, the Bering Strait and the Bering Sea, then through the Pacific, roughly on the $180^{\circ}$ meridian, bypassing / leaving Aleutian Islands of Alaska to the east, and zigzagging among a few islands of the Pacific - therefore, less populated areas, cutting Antarctica, and reaching the South Pole. 


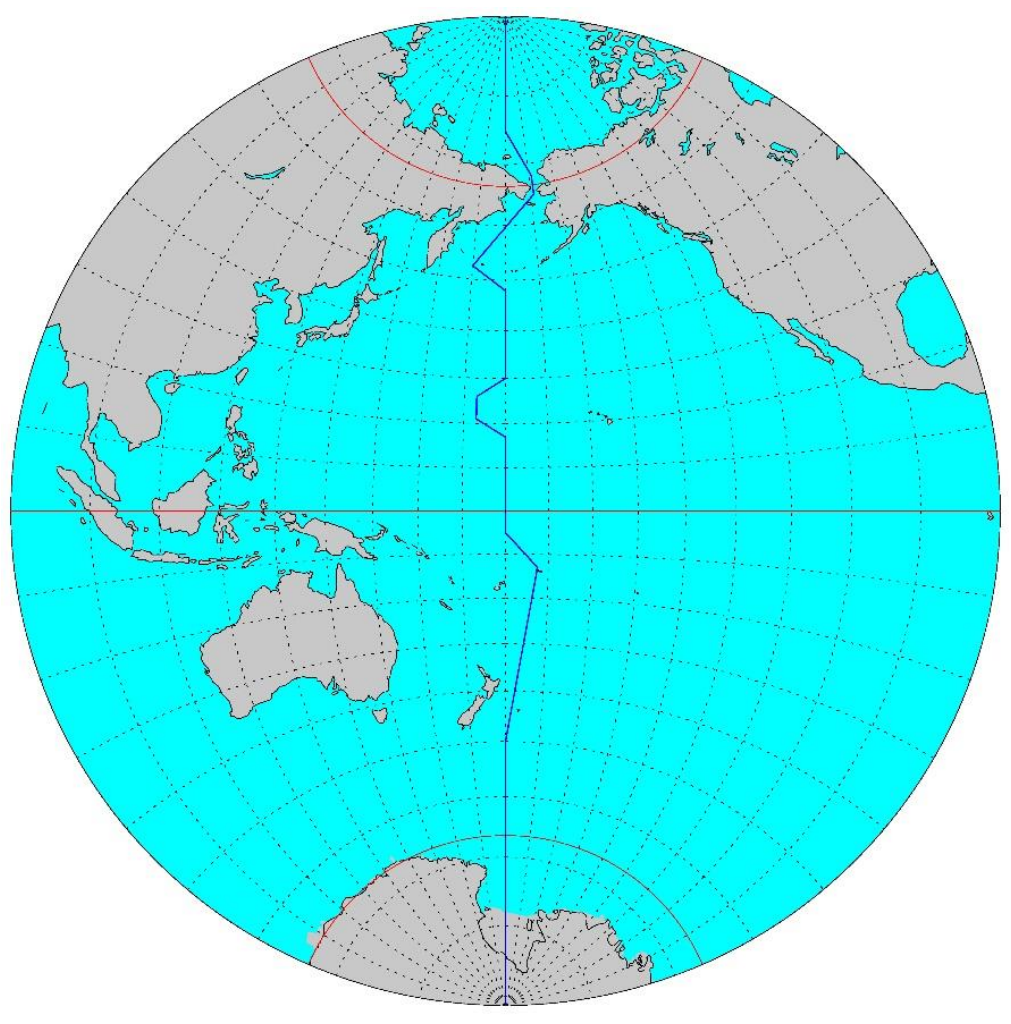

This demarcation line is the first to pass in the new year (roughly $180^{\circ}$ meridian), followed by the meridians: $165^{\circ} \mathrm{East}, 150^{\circ} \mathrm{E}, 135^{\circ} \mathrm{E}, 120^{\circ} \mathrm{E}$; $105^{\circ} \mathrm{E}, 90^{\circ} \mathrm{E}, 75^{\circ} \mathrm{E}, 60^{\circ} \mathrm{E}, 45^{\circ} \mathrm{E}, 30^{\circ} \mathrm{E}$, $15^{\circ} \mathrm{E}, 0^{\circ}, 15^{\circ} \mathrm{West}, 30^{\circ} \mathrm{W}, 45^{\circ} \mathrm{W}, 60^{\circ} \mathrm{W}, 75^{\circ} \mathrm{W}, 90^{\circ} \mathrm{W}, 105^{\circ} \mathrm{W}, 120^{\circ} \mathrm{W} ; 135^{\circ} \mathrm{W}, 150^{\circ} \mathrm{W}, 165^{\circ}$ W.

Consequently, every New Year is celebrated 24 times. The first to celebrate are the inhabitants of the Pacific Islands: Apia, Nuku'alofa, Funafuti, Suva, and of the remote east of Siberia (Provdeniya), and of the Wrangel Island of Siberia. And the last to celebrate it: the inhabitants of the most western Aleutian islands, plus those in the Pacific islands: Midway, Pago Pago, Alofi, Johnson Atoll, Avalua, Cook Islands. 


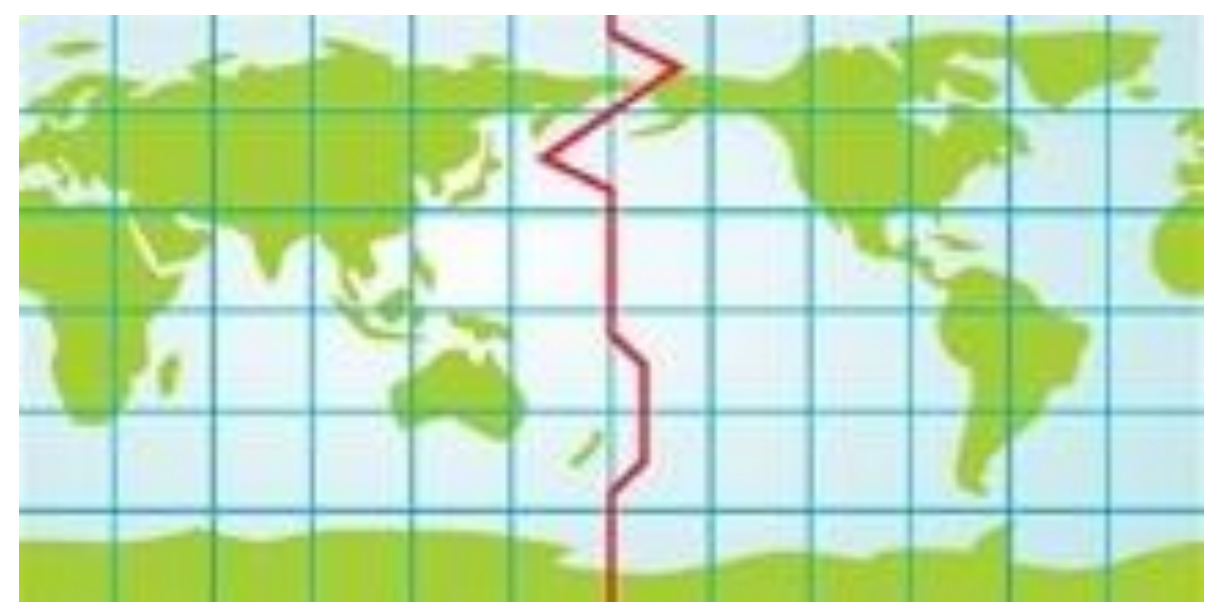

There are 24 New Year's Eve annually, due to the planetary convention that each time-zone is $2 \pi / 24=\pi / 12=15^{\circ}$, or:

$$
\frac{360^{0}}{15^{0}}=24 \text { time-zones. }
$$

In general, if a time-zone has $d^{0}, d>0$, then there are $\frac{360}{d}$ time-zones, considering $d$ a rational divisor of 360: for example $d=10, \frac{2}{7}, \frac{15}{13}$ etc.

In fact, there is an infinitude of New Year's Eves, because for every meridian between $\left[0^{\circ}\right.$, $180^{\circ}$ East $]$ and $\left[0^{\circ}, 180^{\circ}\right.$ West $]$ respectively, there is a New Year's Eve. Namely: $\lim _{d \rightarrow 0^{+}} \frac{360}{d}=\infty$.

Within 24 hours, from the first to the last, the whole world celebrates the New Year's Eve.

Yet, a person being on the Geographical (Terrestrial) North Pole or on the Geographical (Terrestrial) South Pole celebrates the New Year Ever for 24 hours continuously! [3]

\{ Earth's geographical poles are different from its magnetic poles. \}

\section{Calculating the Difference of Time-Zones.}

How do you know the difference in time-zones between two cities using Airplanes Timetable (knowing: aircraft's departure time, aircraft's arrival time, and aircraft's flight duration)? [4]

There are two Earth's hemispheres, east and west.

The continents: Europe, Asia, Africa, and Australia are in the Eastern Hemisphere. While in the Western Hemisphere: Americas (Northern, Central, and Southern). If the cities are in the 
same hemisphere (Eastern or Western), because the Earth rotates around its axis from the West to the East, the eastern city will be ahead with the time-zone.

\subsection{First Example:}

My plane leaves Chicago at 20:20 and arrives in Albuquerque at 22:25 after $3 \mathrm{~h} 5 \mathrm{~min}$ of flight.

Chicago is east of Albuquerque, so ahead with the time-zone.

$20: 20+3: 05=23: 25$.

If it had the same time-zone, then the airplane should have reached Albuquerque at 23:25, not at $22: 25$.

The difference of one hour 23: $25-22: 25=1: 00$ is precisely the time-zone difference, so Albuquerque is one hour past Chicago.

\subsection{Second Example.}

The problem is complicated when cities are in different hemispheres.

Example: Tokyo is in the eastern hemisphere, and Chicago in the west.

My American Airlines plane left Tokyo on Monday, January 8th, 2018, at 18:15, and landed in Chicago still on Monday, January 8th, 2018, but at 15: 10, after 11h 55min flight hours! How is that possible? So, at about 3 hours back in time!

Instead of considering the relative time (the time-zone), we can consider the absolute (mathematical) time that is the same all over the globe.

18: $15+11: 55=30: 10$.

Being in different hemispheres, the western hemisphere city (Chicago) is behind the eastern hemisphere city (Tokyo).

Since 30: $10>24: 00$, it does not exist, and we subtract one days (24h):

Therefore, 30:10-24:00 =6:10, in other words, if these two cities had the same timezone, I would have arrived at 6:10 the following day (January 9th, 2018). And then: 15: $10-$ 6: $10=9: 00$, that is, the city of Chicago is 9 hours behind Tokyo.

\section{Conclusion.}


In this paper we explain how it is possible for a person to celebrate 24 New Year' Eves within a single year, and that somebody staying on the North or South Pole celebrates the New Year Eve... 24 hours continuously!

\section{References:}

[1] World Book Encyclopedia Vol 5. Illinois: Field Enterprises Educational Corporation: 1961: 13.

[2] Serway, Raymond A., Beichner, Robert J., Jewett, John W. Physics for Scientists and Engineers with Modern Physics: Fifth Edition. Orlando, FL: Saunders College Publishing, 2000: 317 Q10.

[3] Smarandache, Florentin, Ocolul Pământului cu Avionul, Editura Agora, Sibiu, 2018.

[4] Smarandache, Florentin, Pe Drumuri Neutrosofice Pakistaneze, Editura Agora, Sibiu, 2018. 